\title{
Wnt Regulates Axon Behavior through Changes in Microtubule Growth Directionality: A New Role for Adenomatous Polyposis Coli
}

\author{
Silvia A. Purro, ${ }^{\star}$ Lorenza Ciani, ${ }^{\star}$ Monica Hoyos-Flight, ${ }^{\star}$ Eleanna Stamatakou, Eliza Siomou, and Patricia C. Salinas \\ Research Department of Cell and Developmental Biology, University College London, London WC1E 6BT, United Kingdom
}

\begin{abstract}
Axon guidance and target-derived signals control axonal behavior by regulating the cytoskeleton through poorly defined mechanisms. In particular, how these signaling molecules regulate the growth and directionality of microtubules is not well understood. Here we examine the effect of Wnts on growth cone remodeling, a process that precedes synapse formation. Time-lapse recordings reveal that Wnt3a rapidly inhibits growth cone translocation while inducing growth cone enlargement. These changes in axonal behavior are associated with changes in the organization of microtubules. Time-lapse imaging of EB3-GFP (green fluorescent protein)-labeled microtubule plus-ends demonstrates that Wnt3a regulates microtubule directionality, resulting in microtubule looping, growth cone pausing, and remodeling. Analyses of Dishevelled-1 (Dvl1) mutant neurons demonstrate that Dvll is required for Wnt-mediated microtubule reorganization and axon remodeling. Wnt signaling directly affects the microtubule cytoskeleton by unexpectedly inducing adenomatous polyposis coli (APC) loss from microtubule plus-ends. Consistently, short hairpin RNA knockdown of APC mimics Wnt3a function. Together, our findings define APC as a key Wnt signaling target in the regulation of microtubule growth direction.
\end{abstract}

Key words: neurons; Wnt; Dishevelled; Gsk3; microtubules; APC

\section{Introduction}

The formation of a functional nervous system requires the proper navigation and terminal remodeling of axons. Members of the Wnt family of secreted proteins can function as axon pathfinding cues and target-derived factors that regulate axon terminal arborization (Umemori et al., 2004; Ciani and Salinas, 2005; Zou, 2006). During early stages of synapse formation, Wnts can act retrogradely to induce axonal remodeling, a process characterized by axonal spreading and growth cone enlargement (Hall et al., 2000; Krylova et al., 2002). Importantly, loss of Wnt7a or Dishevelled-1 (Dvl1), a key component of the Wnt pathway, causes severe defects in the terminal remodeling of axons in vivo (Hall et al., 2000; Ahmad-Annuar et al., 2006). Although these changes are accomplished through modifications in the axonal cytoskeleton, the precise effects of Wnt signaling on the cytoskeleton are poorly characterized.

Profound changes in the organization of microtubules (MTs) are associated with terminal remodeling during synapse formation. Studies at the Drosophila neuromuscular junction (NMJ)

Received July 18, 2008; revised June 26, 2008; accepted July 11, 2008.

This work was supported by the Wellcome Trust and the Biotechnology and Biological Sciences Research Council. We thank Drs. Daniel Sussman and Tony Wynshaw-Boris for generously providing the Dvl1 mutant mice, Niels Galjart, Britta Eickholt, Robert Kypta, Avri Ben-Ze'ev, Inke Nathke, Jos Veldscholte, Jeremy Nathans, and Calum Sutherland for constructs and reagents, and Peter Baas, Louise Crammer, and Britta Eickholt for helpful discussions. We also thank members of our laboratory for useful discussion and comments on this manuscript.

*S.A.P., L.C., and M.H.-F. contributed equally to this work.

Correspondence should be addressed to Patricia C. Salinas, Research Department of Cell and Developmental Biology, University College London, London WC1E 6BT, UK. E-mail: p.salinas@ucl.ac.uk.

DOI:10.1523/JNEUROSCI.2320-08.2008

Copyright $\odot 2008$ Society for Neuroscience $\quad$ 0270-6474/08/288644-11\$15.00/0 have shown that MTs form loops and grow backward, away from the leading edge of the synaptic bouton (Packard et al., 2002). Importantly, this MT organization contributes to changes in synaptic bouton size and shape and is regulated by Wingless/Wnt (Packard et al., 2002). Studies using cultured neurons have revealed that during axon outgrowth, MTs splay and orient along the axis of extension such that their plus-ends are captured at the leading edge of the growth cone by MT plus-end-binding proteins (+ TIPs) such as adenomatous polyposis coli (APC), CLIP170, and EB1 (for review, see Galjart, 2005). In the presence of Wnts, in contrast, MTs form loops as observed in synaptic boutons (Hall et al., 2000). This MT reorganization is likely to determine changes in axon behavior. Although + TIPs could contribute to changes in MT behavior, little is known about the effect of extracellular cues on the localization or function of + TIPs in axons.

Here, we have examined the mechanism by which Wnts induce axon terminal remodeling. Time-lapse recordings show that Wnt3a rapidly decreases the speed of growth cone advance while increasing growth cone size. This remodeling is induced by activation of a canonical Wnt- $\beta$-catenin pathway that is independent of transcription. Recordings of MTs labeled with the MT plusend-binding protein EB3-green fluorescent protein (GFP) reveal that Wnt3a induces the loss of MT growth directionality, resulting in MT looping. During axon elongation, APC is localized at MT tips in growth cones (Zhou et al., 2004; Gärtner et al., 2006). In contrast, during axon remodeling, Wnt3a decreases endogenous APC from MT plus-ends at the leading edge. Importantly, APC knockdown mimics Wnt-induced remodeling and MT 
looping. These results are unexpected. Although APC is known to negatively regulate canonical Wnt signaling to the nucleus (Gordon and Nusse, 2006), its regulation and localization to MTs was thought to be independent of Wnt signaling. Our studies demonstrate a novel function for Wnt signaling in regulating MT growth directionality through changes in APC on MT plus-ends.

\section{Materials and Methods}

Neuronal cultures and transfections. DRG neurons were isolated from embryonic day 13.5 (E13.5) or from newborn mice according to Kleitman et al. (1991). Neurons were plated at 180 cells $/ \mathrm{mm}^{2}$ on coverslips coated with poly-D-lysine (Sigma) (100 $\mu \mathrm{g} / \mathrm{ml})$ and laminin (Sigma) $(20$ $\mu \mathrm{g} / \mathrm{ml})$. Neurons were cultured in serum-free medium in the presence of NGF (Alexis Biochemicals) $(50 \mu \mathrm{g} / \mathrm{ml})$. Conditioned medium from GFP- or Wnt3-hemagglutinin (HA)-expressing Rat1B cells or purified Wnt3a $(50 \mathrm{ng} / \mathrm{ml})$ was added $2 \mathrm{~h}$ after plating. For transfections, DRG neurons were electroporated using Amaxa Biosystems. Briefly, dissociated DRGs were centrifuged at $110 \times g$ for 5 min and resuspended in mouse nucleofector solution containing 5-10 $\mu \mathrm{g}$ of DNA. Different DNA constructs were used: enhanced GFP (EGFP), EB3-EGFP, Dvl1HA, Gsk3 $\beta$ S9A-HA, Armadillo $\beta$-catenin-HA, APC1 shRNApSuper, APC2 shRNApSuper, APC3 shRNApSuper, and scrambled shRNApSuper. Expression of proteins was detected $16 \mathrm{~h}$ after transfection. For glycogen synthase kinase-3 (Gsk3) inhibition, neurons were treated with $100 \mathrm{~nm}$ 6-bromoindirubin-3'-oxime (Bio) (EMD Biosciences) or $2 \mu \mathrm{M}$ CHIR 99201 (6-\{2-[4-(2,4-dichloro-phenyl)-5-(4-methyl-1H-imidazol2-yl)-pyrimidin-2-ylamino]-ethylamino\}-nicotinonitrile; kindly provided by Dr. Calum Sutherland, University of Dundee, Dundee, UK) for $2 \mathrm{~h}$. To block actin dynamics or to induce low levels of actin depolymerization, neurons were treated with $100 \mathrm{~nm}$ or $1 \mu \mathrm{m}$ latrunculin B (Sigma), respectively, for $30 \mathrm{~min}$ before addition of Wnt 3 a or vehicle for a period of $2 \mathrm{~h}$.

Time lapse. Time-lapse experiments were performed on an inverted Axiovert Zeiss 200 microscope with a heated stage and $\mathrm{CO}_{2}$ chamber. Images were collected using MetaMorph software. For long-term recordings $(9 \mathrm{~h})$, frames were captured every $2 \mathrm{~min}$. To analyze the movements of EB3 comets, frames were taken every $3 \mathrm{~s}$ over a period of 2-3 min.

Wnt conditioned media. Wnt3-conditioned media was obtained from Rat1B cells stably transfected with HA-tagged Wnt 3 cDNA. Antibioticresistant, non-Wnt-expressing Rat1B cells were used as controls. The level of Wnt3-HA protein was monitored by Western blot using anti-HA antibody (Roche Diagnostics), and Wnt3 activity was assessed by $\beta$-catenin stabilization in L cells. Purified Wnt3a was purchased from $\mathrm{R} \& D$ Systems and used at a concentration of $50 \mathrm{ng} / \mathrm{ml}$.

Mutant mice. C57BL/6J Dvl-1 null mice were obtained from heterozygous crosses. Genomic tail DNA was used for genotyping the animals using PCR amplification. The primers used were forward $D v l 1$ primer $\left(5^{\prime}\right.$-tctgcccaattccacctgcttctt), the reverse Dvll primer $\left(5^{\prime}\right.$-cgccgccgatcccctctc), and the forward Neo primer (5'-aggcctacccgcttccattgctca).

APC knockdown using short hairpin RNA. NB2a neuroblastoma mouse cells were transfected with EGFP, scrambled shRNApSuper, APC1 shRNApSuper, APC2 shRNApSuper, and APC3 shRNApSuper using Lipofectamine (Invitrogen). The last three vectors target different regions of the same APC gene. After $2 \mathrm{~d}$ of transfection, total RNA was isolated using RNeasy Mini kit (Qiagen). cDNA was synthesized using AMV (avian myeloblastosis virus) reverse transcriptase (Promega). Amplification of cDNA samples was performed using primers APC-forward $(\mathrm{Fw})$ 5 '-tccacaacatcattcactcacag and APC-reverse (Rv) 5'-tccaaagcacattccatcaa to detect APC. As control, the levels of 18S RNA were detected using $18 \mathrm{~S}-\mathrm{Fw} 5^{\prime}$-ccgcgaaagagtcctgta and $18 \mathrm{~S}-\mathrm{Rv} 5^{\prime}$-gggaacgcgtgcatttat primers. PCR products were separated by electrophoresis in $2 \%$ agarose gel. Two isoforms (probably resulting from alternative splicing) were detected for APC. The level of APC knockdown was assessed by the ratio of APC over 18S PCR products.

Immunofluorescence microscopy. Neurons were fixed in 4\% PFA-4\% sucrose at room temperature for $20 \mathrm{~min}$, permeabilized with $0.05 \%$ Triton X-100 for $5 \mathrm{~min}$, and blocked in 5\% BSA in PBS for $1 \mathrm{~h}$. When it was necessary to look only at the cytoskeleton, neurons were fixed with $3 \%$ formaldehyde and $0.2 \%$ gluteraldehyde in the presence of $0.2 \%$ Triton $\mathrm{X}-100$ for $10 \mathrm{~min}$ at $37^{\circ} \mathrm{C}$. Primary antibodies against Dvll (Krylova et al., 2000), tyrosinated tubulin (Abcam), GAP-43 (Abcam), EGFP (Millipore), APC (kindly provided by Dr I. Nathke, University of Dundee, Dundee, UK), CLIP170 (Santa Cruz Biotechnology), and EB1 (Signal Transduction) were used. Alexa488-, Alexa546-, Alexa647-, and phalloidin-conjugated secondary antibodies (Invitrogen) were used. Images were captured with an inverted Zeiss M200 microscope using a CCD camera (Orca ER).

Image analysis and quantification. MetaMorph software was used to acquire and analyze the images. Twenty random fields per coverslip were acquired and analyzed. The drawing tool was used to delineate axons (defined as the longest process), MT tips, and trace growth cones. Axons were measured from the axon hillock to the distant edge of the growth cone. All graphs are the result of at least three independent experiments. Branching order was measured by defining the first point of divergence from the main axon as secondary branches. Tertiary branches result from the next point of divergence. Growth cones with looped MTs were those containing at least $30 \%$ of their MTs bent at an angle of $90^{\circ}$ or bigger. Kymographs were obtained using ImageJ software. Z-Stacks of consecutives frames were projected for the most highly intense comets, and the last frame was labeled in red to indicate directionality. Two-factor ANOVA test was used to determine statistically significant differences between treatments.

\section{Results}

\section{Wnt3a induces axonal remodeling in neonatal DRG sensory neurons}

We have previously shown that Wnt3 induces axonal remodeling in NT3-responsive DRG cells from E13.5 (Krylova et al., 2002). Here we show that Wnt3 also induces remodeling in neonatal DRGs (supplemental Fig. $1 A$, available at www.jneurosci.org as supplemental material). To elucidate the sequence of events leading to Wnt-induced axon remodeling, we decided to establish a reliable system in which Wnt function can be examined. We first examined whether purified $\mathrm{Wnt} 3 \mathrm{a}$, a protein highly related to Wnt3, induces remodeling in DRG neurons. We found that Wnt3a induces a 30\% increase in the average size of growth cones after $2 \mathrm{~h}$ (supplemental Fig. $1 B, C$, available at www.jneurosci.org as supplemental material), which was manifested by a shift toward larger growth cones (supplemental Fig. $1 D$, available at www.jneurosci.org as supplemental material). Axon branching and length are also affected as the number of tertiary and quaternary branches increases (supplemental Fig. $1 B, E$, available at www.jneurosci.org as supplemental material), whereas axon length decreases (supplemental Fig. 1B,F, available at www. jneurosci.org as supplemental material). The effect of purified Wnt3a or Wnt3-conditioned medium remain unchanged for at least $22 \mathrm{~h}$ as a similar increase in growth cone size and branching is observed compared with $2 \mathrm{~h}$ exposure to Wnt (supplemental Fig. $1 B, C, E$, available at www.jneurosci.org as supplemental material). Together, these results indicate that Wnt3-conditioned media and purified Wnt3a have a similar remodeling activity in embryonic and neonatal sensory neurons and that exposure to $\mathrm{W}$ ts for only $2 \mathrm{~h}$ is sufficient to induce remodeling. Because of the more reproducible effect with purified Wnt3a, all subsequent experiments were performed with Wnt3a purified protein.

\section{Wnt3a induces rapid changes in axonal behavior: analyses by time-lapse microscopy}

To examine in detail the effect of Wnts on axonal remodeling, we performed time-lapse experiments. DRG neurons were transfected with EGFP before plating and cultured for $\sim 5 \mathrm{~h}$ to allow gene expression. Recordings began $20 \mathrm{~min}$ before the addition of Wnt3a or control media, and frames were taken every 2 min for a 
period of up to $9 \mathrm{~h}$ after Wnt3a addition. Control axons grow at a steady rate, undergo few branching events, and display no significant changes in growth cone size (Fig. $1 A$; supplemental Video $1 A$, available at www.jneurosci.org as supplemental material). In contrast, axons exposed to Wnt3a extend at much slower rates, branch more, and exhibit a steady increase in growth cone size (Fig. $1 \mathrm{~B}$; supplemental Video $1 B$, available at www.jneurosci.org as supplemental material). No differences in the number of collapsed growth cones were observed. Quantification demonstrates that Wnt 3 a reduces the speed of growth cone advance within the first 20 min of Wnt addition (data not shown). The average speed of growth cone advance, $20 \mathrm{~min}$ after addition of control media, was $0.32 \mu \mathrm{m} / \mathrm{min}$, whereas the average speed of growth cone advance 20 min after Wnt3a addition was $0.07 \mu \mathrm{m} /$ min. Despite the slower growth cone advance, Wnt3a increases the membrane protrusion in growth cones and at the distal portion of axons (Fig. $1 B$; supplemental Video $1 B$, available at www.jneurosci.org as supplemental material). Over time, control growth cones become smaller or maintain their size, whereas Wnt3atreated growth cones slowly but steadily increase their size. This effect becomes more apparent after $60 \mathrm{~min}$ of Wnt3a exposure (Fig. $1 B$ ). On average, Wnt3a induces a $55 \%$ increase in growth cone size, whereas control growth cones decrease in size by $20 \%$. These findings demonstrate that Wnt3a induces rapid changes in axon and growth cone behavior.

\section{Wnt- $\beta$-catenin signaling pathway regulates axon remodeling independently of transcription}

Wnts are known to signal through three main pathways to regulate cell fate, polarity and behavior. Through different receptors, Wnts can activate the canonical or $\beta$-catenin pathway, resulting in Gsk3 inhibition, elevation of $\beta$-catenin, and transcriptional activation. Wnts also signal through a Rho GTPases and JNK pathway or through a calcium/ calmodulin pathway (Gordon and Nusse, 2006). Although the canonical pathway has been well studied for its role in transcription-mediated changes, recent studies demonstrate that components of this pathway interact with or regulate the cytoskeleton directly (for review, see Salinas, 2007). To begin to dissect the mechanism by which Wnts induce axon remodeling, we focused our study on the canonical Wnt pathway, because Gsk3 directly phosphorylates several cytoskeletal proteins; therefore, changes in Gsk3 activity could affect axon behavior (Lucas et al., 1998; Goold et al., 1999; Shi et al., 2004; Gärtner et al., 2006; Kim et al., 2006).

We first examined the contribution of Dvl, a protein required for Wnt signaling but that also binds to both MTs and actin filaments (Krylova et al., 2000; Torres and Nelson, 2000; Capel-
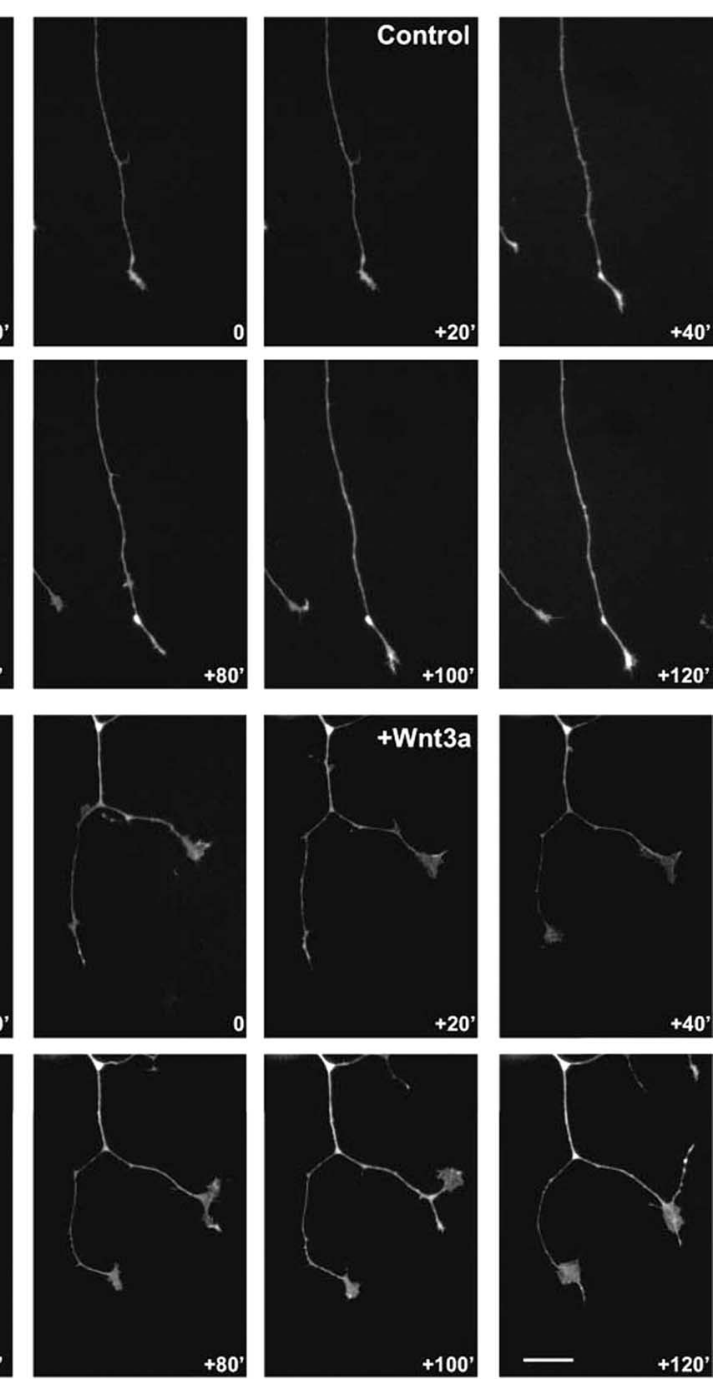

Figure 1. Wnt3a induces changes in axon behavior. $\boldsymbol{A}$, Frames from a time-lapse recording illustrating the typical response of become enlarged. Scale bar, $20 \mu \mathrm{m}$. Wnt3a decreases the speed of growth cone advance within $20 \mathrm{~min}$ and increases growth cone size after 60 min (supplemental Video 1A, B, available at www.jneurosci.org as supplemental material).

luto et al., 2002). To test whether Dvl mediates Wnt3a-induced axonal remodeling, we examined the effects of Dvl expression on neuronal morphology. Dvl1 causes significant changes in the axonal morphology of DRGs, as axons become shorter and thicker and growth cones are larger than GFP-expressing control axons (Fig. 2A). Quantification reveals that Dvl1 increases growth cone size by $30 \%$ (Fig. 2 B). In addition, expression of Dvll results in a $17 \%$ decrease in axonal length compared with GFP controls (supplemental Fig. $2 B$, available at www.jneurosci.org as supplemental material) and, like Wnt3 and Wnt3a, Dvl1 expression increases the number of branches (supplemental Fig. 2C, available at www.jneurosci.org as supplemental material). To examine the Wnt pathway involved in remodeling, we tested the contribution of Gsk $3 \beta$, a serine/threonine kinase that is inhibited by Wnts in the canonical pathway (Gordon and Nusse, 2006). Inhibition of Gsk3 by Bio and CHIR 99021, two specific pharmacological inhibitors (Ring et al., 2003; Cohen and Goedert, 2004), induces extensive axon remodeling (Fig. 2C,D; supplemental Fig. $2 D$, available at www.jneurosci.org as supplemental material). Inter- 
A
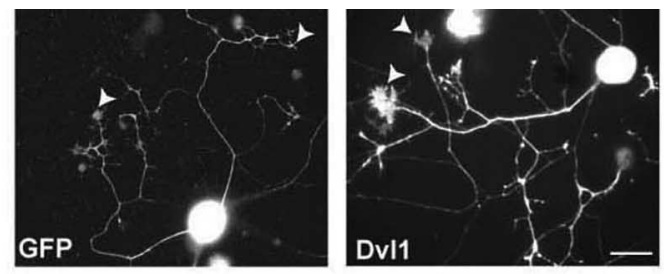

C

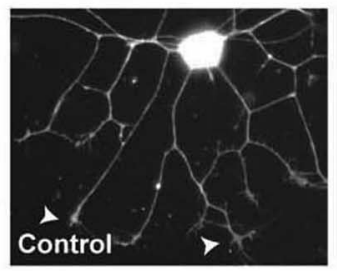

E

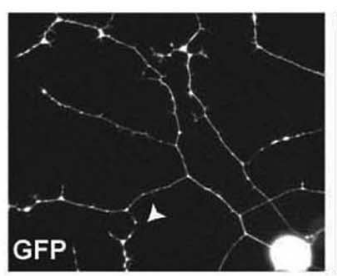

G
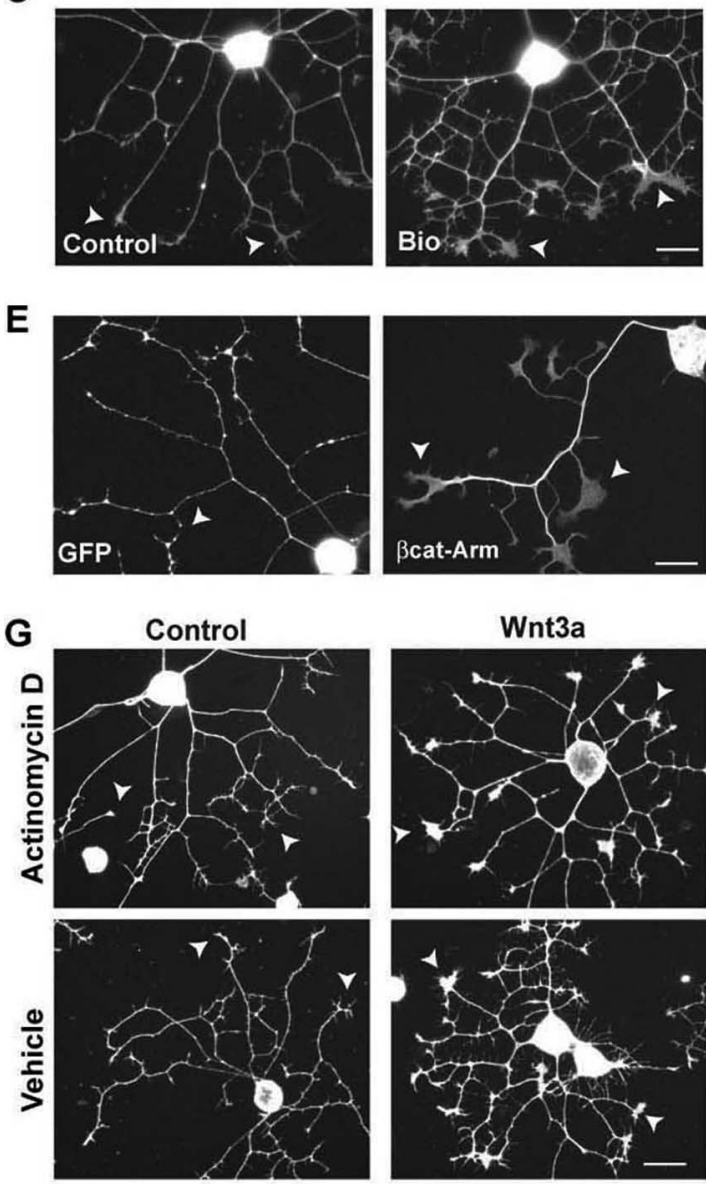

Wnt3a

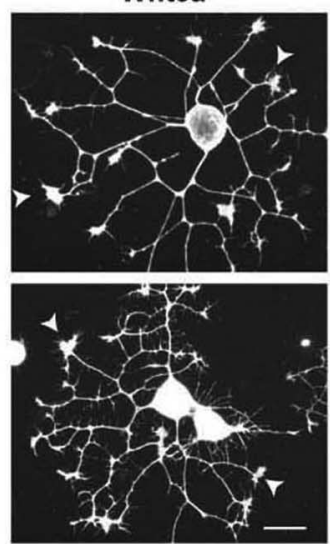

B

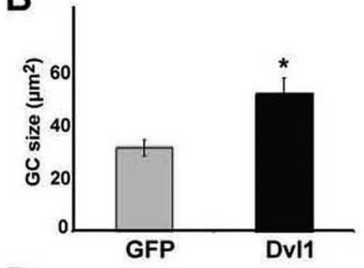

D

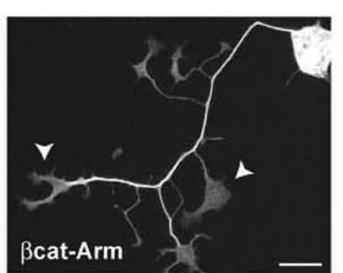

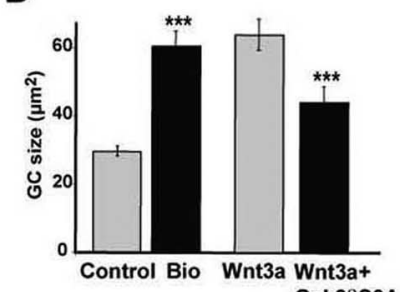

$\mathbf{F}$

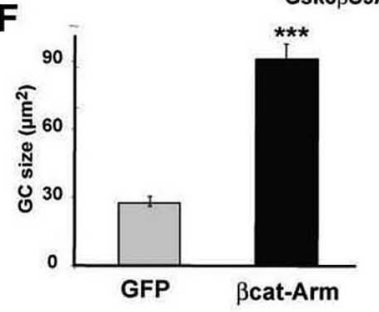

H

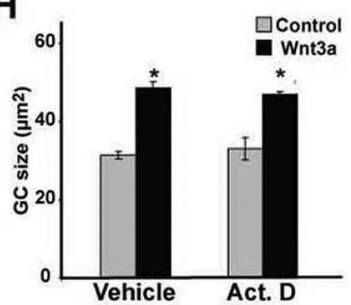

Figure 2. Wnt3a-induced axonal remodeling is mimicked by Dvl1 or $\beta$-catenin and inhibition of Gsk3 $\beta$ but does not require transcription. $A$, Expression of Dvl1 in DRG neurons induces growth cone enlargement (arrowheads), axon shortening, and branching compared with control EGP-expressing neurons. Scale bar, $30 \mu \mathrm{m}$. B, Quantification of growth cone (GC) size reveals a $30 \%$ increase in Dvl1-expressing cells compared with controls. C, Application of the Gsk3-specific pharmacological inhibitor Bio for $2 \mathrm{~h}$ mimics the effect of Wnt3a on axon remodeling (arrowheads). Scale bar, $30 \mu \mathrm{m}$. D, Quantification shows a significant increase in the size of growth cones (30\%) in the presence of Bio. Expression of a constitutive form of Gsk3 $\beta$ (Gsk3 $\beta 59 \mathrm{~A}$ ) partially blocks the effect of Wnt3a on growth cone size. $\boldsymbol{E}$, Expression of $\beta$-catenin-Arm ( $\beta$-cat-Arm) induces growth cone enlargement in DRG neurons (arrowheads) compared with control EGP-expressing neurons. Scale bar, $30 \mu \mathrm{m}$. $\boldsymbol{F}$, Quantification of growth cone size reveals a $60 \%$ increase in $\beta$-catenin-Arm-expressing cells compared with controls. $G$, Wnt3a induces axonal remodeling (arrowheads) in the presence of actinomycin D. Scale bar, $30 \mu \mathrm{m}$. $\boldsymbol{H}$, Average growth cone size is significantly larger in DRGs exposed to both Wnt3a and actinomycin D (Act. D) than in controls and indistinguishable from neurons treated with both Wnt3a and vehicle. Values are mean \pm SEM of three independent experiments. ${ }^{*} p<0.05 ;{ }^{* * *} p<0.001 . n=50$.

estingly, time course experiments showed that inhibition of Gsk3 by Bio induces a significant enlargement of growth cone size after 60 min of treatment (supplemental Fig. 2E, available at www. jneurosci.org as supplemental material). To further test the role of Gsk3, we examined the effect of Wnt3a on DRG neurons expressing a constitutive active form of Gsk $3 \beta$ (Gsk $3 \beta$ S9A). We found that expression of Gsk3 $\beta$ S9A partially blocks the Wnt effect on growth cone size (Fig. 2D). These results suggest that Wnt3a regulates axon remodeling through a pathway involving Dvll and inhibition of Gsk3 $\beta$.
We then examined the role of $\beta$-catenin, which lies downstream of Gsk $3 \beta$. We found that expression of $\beta$-catenin mimics the effect of Wnt by inducing growth cone enlargement (data not shown). Results from time-lapse experiments demonstrated that Wnt3a induces changes in axon growth within $20 \mathrm{~min}$. This finding raises the possibility that Wnt3a may regulate axon behavior through a nuclear independent mechanism, as observed with a number of guidance molecules (Campbell and Holt, 2001). Consistent with this finding, expression of a mutant $\beta$-catenin ( $\beta$ catenin-Arm), which does not signal to the nucleus because of the lack of the transactivating domain, also induces remodeling (Fig. 2E,F). These results suggest that Wnt signaling modulates axon remodeling through $\beta$-catenin but independently of transcription.

To shed further light on the mechanism by which Wnt3a regulates axonal morphology, we inhibited transcription with actinomycin D. DRG neurons were treated with $10 \mu \mathrm{g} / \mathrm{ml}$ actinomycin $\mathrm{D}$ for $30 \mathrm{~min}$ before addition of Wnt $3 \mathrm{a}$ and examined after $2 \mathrm{~h}$ of exposure to Wnt. We have previously shown that this concentration of actinomycin D completely blocks transcription (Ciani et al., 2004). Actinomycin $\mathrm{D}$ does not block the Wnt3a effect on growth cones size (Fig. 2G,H), indicating that Wnt3a induces axonal remodeling independently of transcription.

\section{Wnt3a signaling regulates axon remodeling through changes in microtubule organization}

Our previous studies in mossy fiber axons have shown that Wnt induces changes in the MT cytoskeleton (Hall et al., 2000). We therefore decided to examine whether Wnt signaling regulates the MT cytoskeleton during remodeling in DRG neurons. In control growth cones, MTs splay in the central region and invade the peripheral domain. In contrast, Wnt3a or expression of Dvll significantly increases the proportion of growth cones containing looped MTs (Fig. 3A,C; supplemental Fig. 2A, available at www.jneurosci.org as supplemental material). Interestingly, MT loops have been described in pausing growth cones (Dent et al., 1999). Thus, our data suggest that the decrease in growth cone advance induced by Wnt3a is associated with MT looping.

We then examined whether Dvll was required for axon remodeling and MTs reorganization. Neurons from Dvl1 mutant mice were exposed to Wnt3a for $2 \mathrm{~h}$, and axon remodeling was assessed by the distribution of dynamic MTs. In the absence of Wnt3a, no apparent differences in axonal outgrowth were observed between Dvll mutant and wild-type neurons (Fig. 3A). In contrast, Dvl1 mutant neurons contain splayed MTs in growth 
A
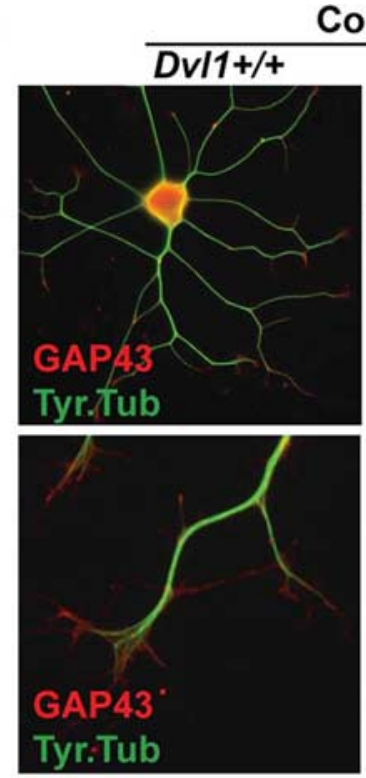

B

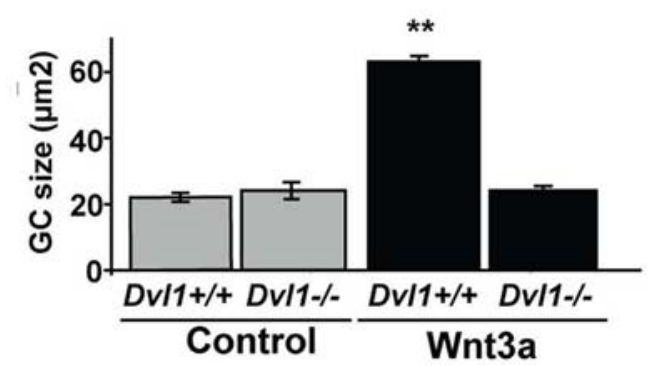

Dvl1-/-
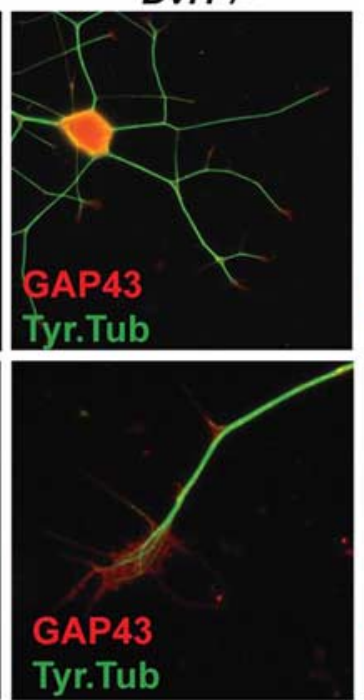

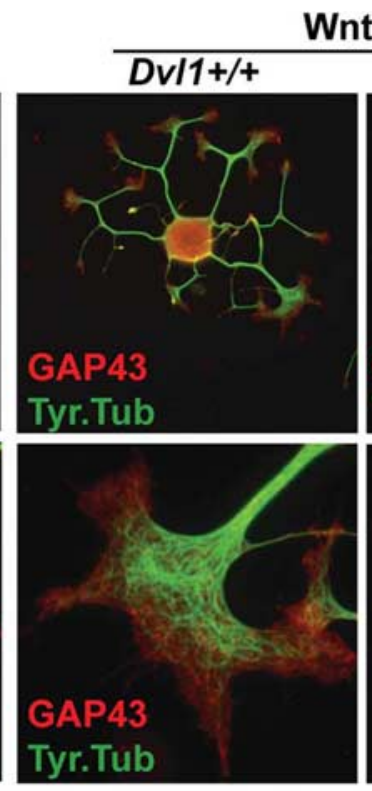

Wnt3a
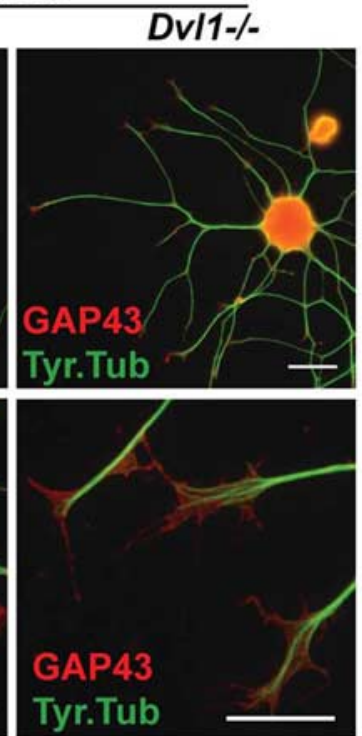

C

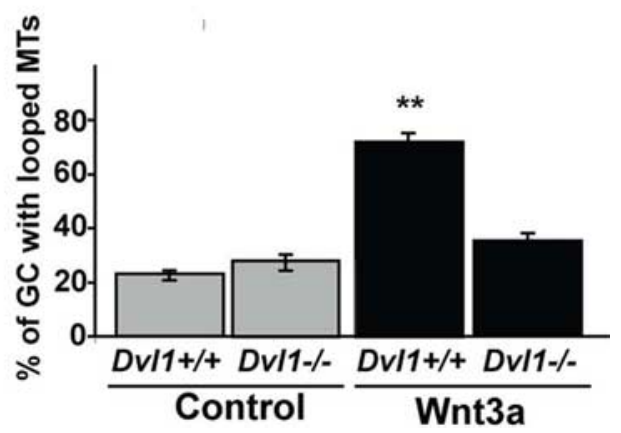

Figure 3. Wnt3a and Dvl1 regulate the amount and organization of microtubules along axons and in growth cones. $A$, DRG neurons from wild-type and Dv/1 mutant mice were exposed to vehicle or Wnt3a for $2 \mathrm{~h}$. In wild-type neurons, Wnt3a induces the formation of looped MTs at growth cones. In contrast, Dv/1 mutant neurons do not remodel, because their axons are long and terminate in small growth cones. Scale bars: top, $30 \mu \mathrm{m}$; bottom, $15 \mu \mathrm{m}$. B, Quantification shows that Wnt3a does not induce growth cone (GC) remodeling in Dv/1 mutant neurons. C, Graph illustrating that Wnt3a does not increase the percentage of growth cones with looped MTs in Dvl1 mutant neurons. Values are mean \pm SEM of three independent experiments. ${ }^{* *} p<0.01 . n=100$.

cones even in the presence of Wnt, indicating that they are unable to respond to Wnt3a (Fig. 3A). Quantification reveals that the growth cone size of Wnt3a-treated Dvl1 mutant neurons remains the same as control untreated neurons (Fig. 3B) and that Wnt3a does not increase the number of cells containing looped MTs compared with untreated wild-type cells (Fig. 3C). These results demonstrate that Dvl1 is required for Wnt3a-induced remodeling and MT organization.

The increased membrane protrusion induced by Wnt3a (Fig. 1 ; supplemental Video $1 B$, available at www.jneurosci.org as supplemental material) raises the possibility that changes in the actin cytoskeleton might contribute to the Wnt-mediated growth cone remodeling. We therefore examined whether Wnt3a induces axon remodeling and MT looping in the presence of latrunculin $\mathrm{B}$, an actin-depolymerizing drug. We used low concentrations of latrunculin B in which actin dynamics is compromised without resulting in total actin depolymerization (Zmuda and Rivas, 2000; Wakatsuki et al., 2001). Pretreatment with 100 nM latrunculin B significantly decreases the length of filopodia in control and Wnt3a-treated neurons (supplemental Fig. $3 A, C$, available at www.jneurosci.org as supplemental material). However, Wnt3a still induces remodeling and MT looping. At $1 \mu \mathrm{M}$ latrunculin B, when growth cones begin to collapse, Wnt3a also induces enlargement of growth cones and the formation of looped MTs (supplemental Fig. $3 A, B$, available at www.jneurosci.org as supplemental material). Although the possibility that Wnt3a affects the actin cytoskeleton cannot be excluded, these results indicate that changes in MT reorganization induced by Wnt3a significantly contribute to the enlargement of growth cones and that Wnts directly signal to the MT cytoskeleton.

Wnt $3 a$ and Dvl1 regulate the organization and directionality of microtubule growth

We next examined in detail the organization of MTs in cultured DRG neurons. As mentioned above, Wnt3a significantly increases the proportion of growth cones containing looped MTs (Fig. 3A). This appearance of looped MTs could be explained by the continued polymerization of MTs in nonadvancing growth cones. Alternatively, Wnt3a could induce a loss of direction of MT growth as they enter at the growth cone.

To begin to distinguish between these two possibilities, we decided to examine the dynamic behavior of MTs. We therefore labeled the plus-ends of MTs by expressing EB3-GFP, a MT plusend-binding protein (Nakagawa et al., 2000), which has been used to examine MT behavior in neurons (Stepanova et al., 2003; Hasaka et al., 2004). In DRG cells, EB3-GFP forms puncta along MTs that rapidly disappear after addition of nocodazole, indicating that EB3-GFP binds to actively growing MTs (data not 
A
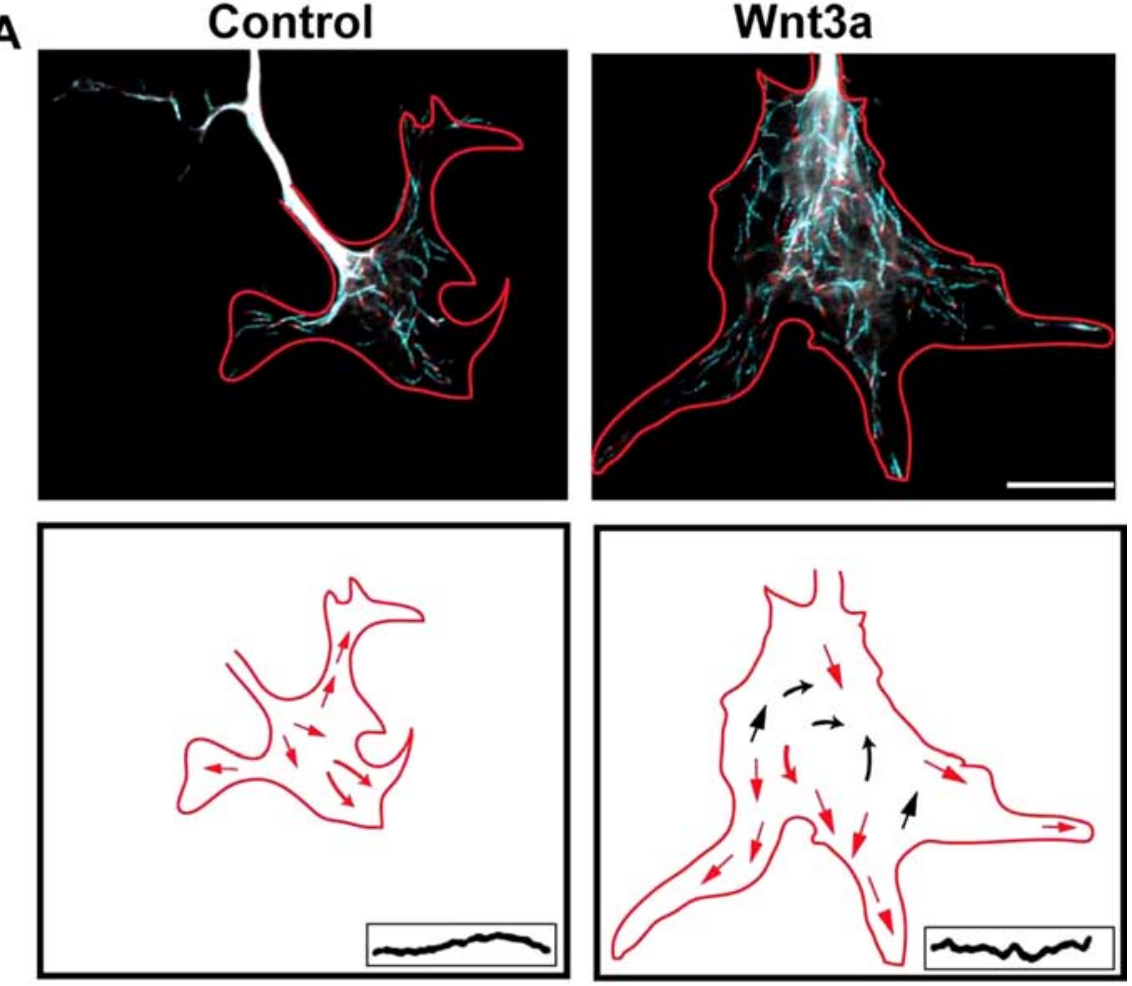

B

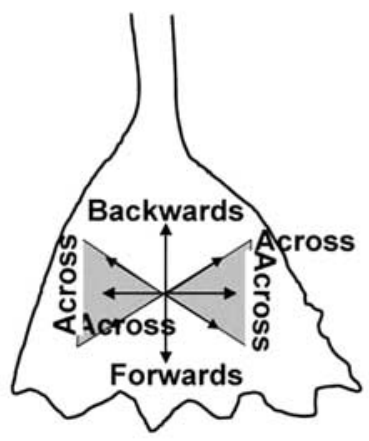

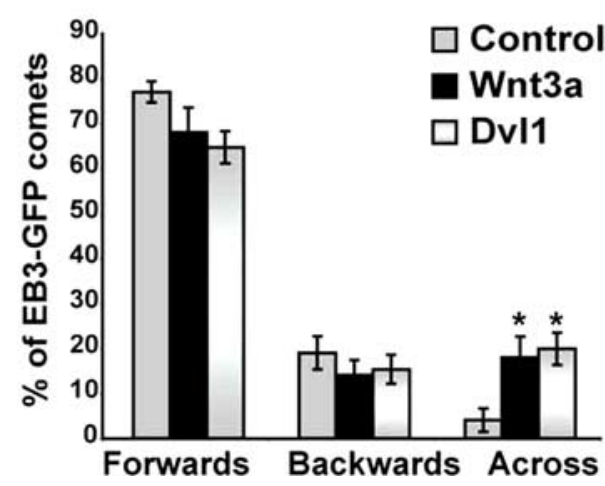

Figure 4. Wnt signaling induces the loss of directionality of microtubule growth. $\boldsymbol{A}$, Kymographs of 10 consecutives frames of a control and Wnt3a-treated growth cone expressing EB3-GFP; the last frame was labeled in red to indicate directionality. In control neurons, most MTs splay as they enter the growth cone (red arrows). In the presence of Wnt3a, the direction of MT growth is altered as more MTs grow across the growth cone (black arrows). Insets, Traces of one representative microtubule from each growth cone. In Wnt3a-treated growth cones, MTs kink several times instead of growing with a persistent directionality. Scale bar, $15 \mu \mathrm{m}$. B, The diagram illustrates how the direction of EB3 comets was quantified. Quantification shows that Wnt3a and Dvl1 significantly increase the number of comets moving across the growth cone while decreasing the number moving forwards, toward the leading edge. The direction of EB3-GFP comets from at least 12 growth cones was analyzed per condition in four independent experiments. Values are mean \pm SEM of at least three independent experiments. ${ }^{*} p<0.05 . n=200$.

shown). Time-lapse recordings of EB3-GFP-labeled MTs enabled us to examine the direction of MT growth. In control neurons, EB3-GFP forms comet-like dashes along the axon shaft, and in growth cones, comet movements reflect the typical splaying behavior of MTs as they move toward the leading edge of the growth cone (Fig. 4A; supplemental Video $2 A$, available at www.jneurosci.org as supplemental material). In contrast, in Wnt3a-treated axons, many of the EB3-GFP comets bend and move across the growth cone before they reach the leading edge (Fig. 4A; supplemental Video $2 B$, available at www.jneurosci.org as supplemental material). Similarly, expression of Dvl1 induces a significant increase in the number of comets moving across the growth cone, even in growth cones of similar size to control (Fig. $4 B$; supplemental Video $2 C$, available at www.jneurosci.org as supplemental material). Quantification revealed that $77 \%$ of the EB3-GFP comets in control neurons grow forwards (toward the leading edge), 19\% of them grow backwards (away from the leading edge, toward the neck of the growth cone and cell body) and a small proportion, 4\%, move across the growth cone (defined as MTs moving perpendicular $\pm 30^{\circ}$ to the direction of growth) (Fig. 4B). In Wnt3a-treated neurons and in Dvl1-expressing neurons, although no statistically significant differences were found in the percentage of comets moving forwards or backwards compared with controls, a tendency for fewer comets moving forwards was observed (Fig. 4B). However, a significantly larger percentage of EB3-GFP comets were found to move across the growth cone in Wnt3a-treated neurons $(18 \%, p<0.05)$. Interestingly, in growth cones exposed to Wnt3a, some MTs display a kinking behavior not observed in control growth cones (Fig. 4A, inset). Because MTs change their direction of growth as they enter the growth cone rather than bending when they reach the leading edge, our findings suggest that MT looping induced by Wnt-Dvl signaling results from the loss of MT growth directionality.

Wnt signaling decreases the level of APC at microtubule plus-ends located at the leading edge of growth cones

+ TIPs have been implicated in MT capture and direction of growth (for review, see Kalil and Dent, 2004, 2005). Therefore, it is possible that the loss of MT directionality, induced by Wnt3a-Dvl signaling, is attributable to changes in the localization or levels of MT plus-end-binding proteins. To address this issue, we examined the distribution of APC, a component of the canonical Wnt pathway (Bienz, 2002) that directly binds to MTs (Zumbrunn et al., 2001). Because Gsk3 $\beta$ phosphorylates APC, resulting in a decreased interaction with MTs (Zumbrunn et al., 2001), we predicted that Wnt3a, which inhibits Gsk $3 \beta$, would increase the level of APC bound to MTs. In DRG neurons, APC localizes to MTs along the axon and at the periphery of growth cones, labeling MT plus-ends (Fig. 5A). Surprisingly, when neurons were treated with $\mathrm{Wnt} 3 \mathrm{a}$ for $2 \mathrm{~h}$, a significant decrease in the level of APC at MT plus-ends at the leading edge of growth cones was observed (Fig. 5A,C). Moreover, APC remains unchanged along the axon shaft of DRG neurons treated with Wnt3a (data not shown), indicating that the decrease in APC observed at the leading edge of the growth cone is not attributable to a general downregulation of APC in the entire neuron. We then examined two other + TIPs, CLIP-170 and EB1, which promote MT rescue and stability, respectively (Tirnauer et al., 1999; Komarova et al., 2002; Rogers et al., 2002; Wen et al., 2004). Interestingly, Wnt3a does not affect the level of EB1 or CLIP-170 
at MT plus-ends in growth cones (supplemental Fig. 4, available at www.jneurosci.org as supplemental material). These results show that Wnt signaling specifically regulates the level of APC at MT plus-ends located at the periphery of growth cones.

To test whether the loss of endogenous APC is correlated with growth cone remodeling, time course experiments were performed. We found that Wnt3a induces a significant loss of APC from MT plusends within $30 \mathrm{~min}$, before a statistically significant increase in growth cone size is detected (Fig. 5B-D). Similarly, the number of growth cones with looped MTs significantly increases after $60 \mathrm{~min}$ (Fig. 5E). Thus, the loss of APC from MT plus-ends precedes growth cone enlargement and the appearance of looped MTs.

We then examined the contribution of Dvl and Gsk3 $\beta$ in APC localization. In neurons from $D v l 1$ mutant mice, Wnt3a does not affect the number of MT tips with APC (Fig. 6B). In contrast, inhibition of Gsk3 induces a significant decrease in the percentage of MTs with APC at their plusends in wild-type or in Dvl1 mutant neurons (Fig. 6A,D). Consistently, inhibition of Gsk3 induces axon remodeling in $D v l 1$ mutant neurons (Fig. $6 A, C$ ). These results demonstrate that Dvll is required for changes in the localization of APC and that Gsk3 $\beta$ lies downstream of Dvl1.

\section{Knockdown of APC induces} microtubule looping in growth cones and increases growth cone size

We then examined whether APC was involved in Wnt-mediated MT looping using a loss-of-function approach. For these experiments, neurons were transfected with three different APC short hairpin RNAs (shRNAs) or with scrambled control shRNA constructs. APC1 and APC2 shRNAs induce a 75\% and APC3 shRNA a $60 \%$ decrease in the level of endogenous APC mRNA compared with neurons expressing scrambled shRNA as control (supplemental Fig. 5A,B, available at www.jneurosci.org as supplemental material). DRG neurons were examined for possible changes in MT looping and growth cone remodeling. In cultures from scrambled shRNA-expressing neurons, only $25 \%$ of growth cones contain looped MTs, similar to control untransfected neurons (Fig. 7A). In contrast, expression of APC1 shRNA induces a significant increase $(66 \%)$ in the number of growth cones with looped MTs (scrambled shRNA, $25 \pm 3$; APC1 shRNA, $73 \pm 3$ ) (Fig. 7A). Importantly, increased MT looping correlates with an increase in growth cone size (growth cone size: scrambled shRNA, $33 \pm 2$; APC1 shRNA, $\left.71 \pm 6 \mu \mathrm{m}^{2}\right)$. We then examined whether the

$\mathbf{B}$

C $n=100$. Scale bars, $5 \mu \mathrm{m}$.
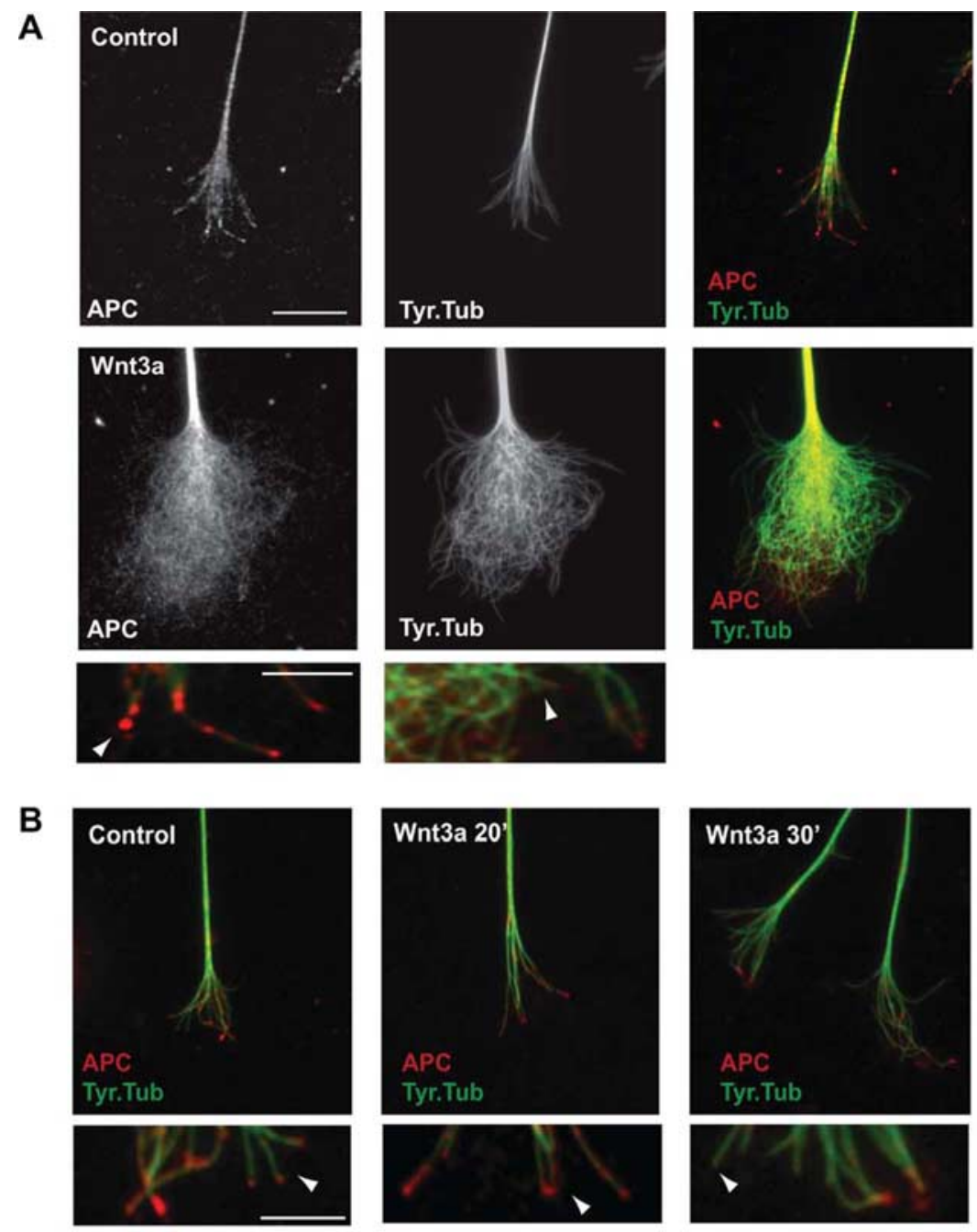

D

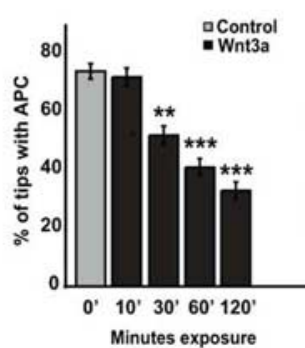

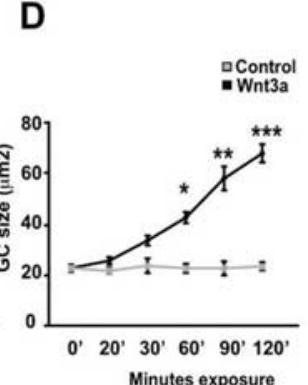

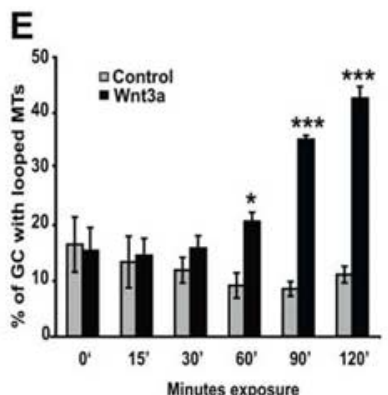

Figure 5. Wnt3a decreases the level of APC at microtubule plus-ends in the periphery of growth cones. $\boldsymbol{A}$, In control DRG neurons, endogenous APC localizes along axonal MTs and at the plus-ends of splayed MTs at the leading edge of the growth cone. Application of Wnt3a for $2 \mathrm{~h}$ decreases the level of APC at MT plus-ends at the leading edge of the growth cone. Enlarged images of growth cones show the significant loss of APC at MT plus-ends (arrowheads) when neurons are exposed to Wnt3a. Scale bar, 15 $\mu \mathrm{m} . \boldsymbol{B}$, Time course experiment shows that APC is lost from MT tips by 30 min after Wnt3a exposure (arrowheads). C, Quantification shows that after 10 min of exposure to Wnt3a, the level of APC at the tips of MTs is similar to control untreated neurons, whereas after 30 min of application, a $25 \%$ loss of APC is observed at the tips of MTs, reaching up to a $55 \%$ after 120 min of Wnt exposure. D, Quantification shows a significant increase in growth cone (GC) size after $60 \mathrm{~min}$ on Wnt treatment. $\boldsymbol{E}$, MT looping correlates with growth cone enlargement. Growth cones from DRG neurons in presence of Wnt3a exhibit more looped MT after 60 min of Wnt exposure. Values are mean \pm SEM of at least three independent experiments. ${ }^{*} p<0.05$; ${ }^{* *} p<0.01$; ${ }^{* * *} p<0.001$.

localization of APC at MT tips was affected in growth cones of APC1 shRNA-expressing neurons. Indeed, $40 \%$ of the endogenous APC is no longer present at MT plus-ends (scrambled shRNA, $86 \pm 4.1$; APC1 shRNA, $51 \pm 4.7$ ), as observed when neurons were treated with Wnt3a (Figs. 5A, 6B). Similar results 
A
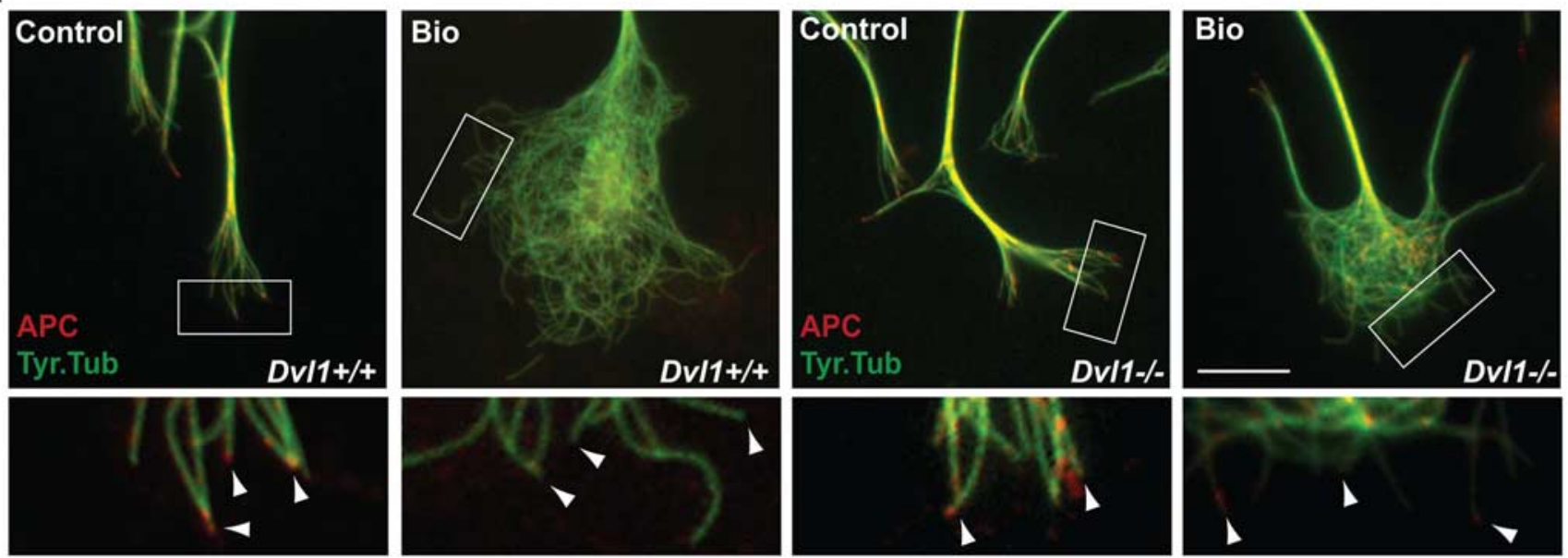

B

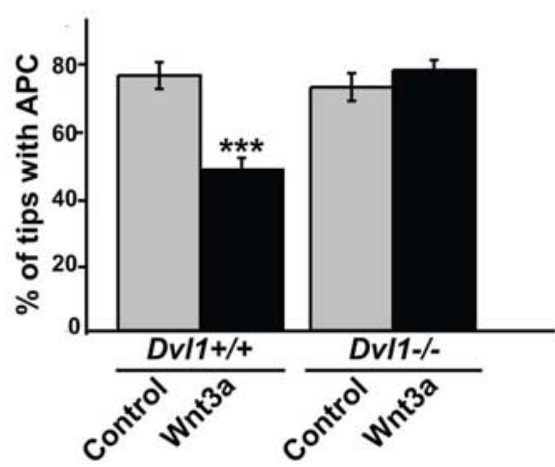

C

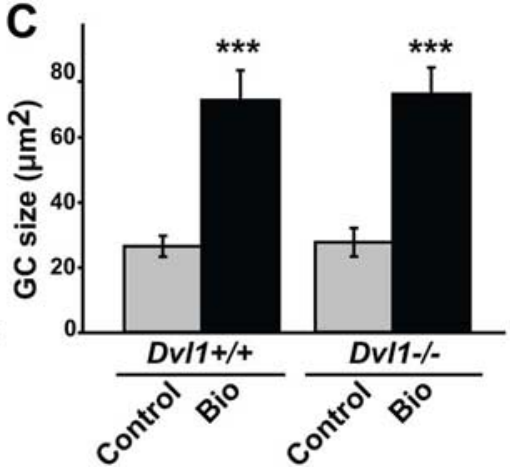

D

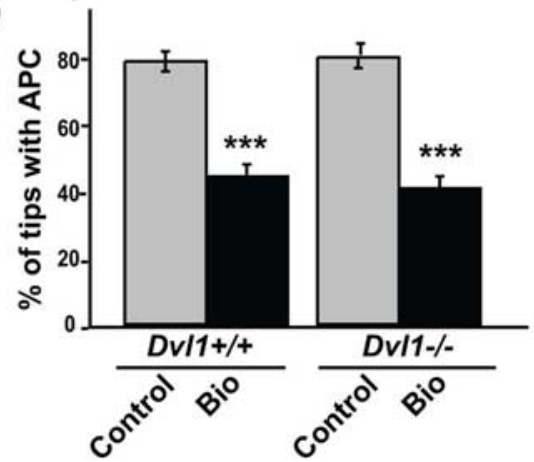

Figure 6. Pharmacological inhibition of Gsk3 decreases the level of APC at microtubule plus-ends of DRG neurons from wild-type or Dv/1 mutant mice. $A$, In DRG neurons from wild-type mice, the Gsk3 inhibitor Bio induces the loss of APC from MT tips at the periphery of the growth cone (arrowheads). Similarly, DRG neurons from Dv11 mutant mice show a decrease in the level of APC at the tips of MTs compared with control neurons (arrowheads). Scale bar, $15 \mu \mathrm{m} . B$, DRG neurons from Dv/1 mutant mice do not show a decrease in the number of MT plus-ends containing APC after Wnt3a treatment compared with untreated neurons. C, Quantification shows that Gsk3 inhibition with Bio increases growth cone (GC) size to the same extent on DRG neurons from wild-type or Dv/1 mutant mice. D, Quantification shows that the percentage of MT tips with APC per growth cone decreases similarly in wild-type or Dv/1 mutant DRG neurons when exposed to Bio. Values are mean \pm SEM of at least three independent experiments. ${ }^{* *} p<0.001 . n=100$.

were obtained using APC2 and APC3 shRNA (supplemental Fig. $5 C-E$, available at www.jneurosci.org as supplemental material). Importantly, all these effects were also observed in $\mathrm{Dvl1}^{-/-}$neurons expressing APC shRNA, confirming again that APC lies downstream of Dvl (scrambled shRNA, $88 \pm 2.10$; APC1 shRNA, $52 \pm 5.2$; thus inducing a $40 \%$ decrease) (Fig. $7 B$ ). These experiments demonstrate that APC is a major target of Wnt-Dvl signaling that regulates axon remodeling and MT looping.

\section{Discussion}

The precise mechanisms by which axon guidance or targetderived signals modulate the cytoskeleton to elicit changes in axon behavior and morphology are poorly understood. Wnt 3 has previously been shown to act as a retrograde signal that controls the terminal arborization of a subset of embryonic DRG neurons (NT-3-responsive neurons) at the time when sensory-motor connections are forming in the vertebrate spinal cord (Krylova et al., 2002). To shed light on the mechanism by which Wnts regulate axon growth and remodeling, we first examined the effects of Wnt proteins on the behavior of axons and the axonal cytoskeleton in live cells. Time-lapse recordings reveal that Wnt3a rapidly reduces the rate of axonal extension (within the first $20 \mathrm{~min}$ ) and subsequently increases membrane protrusion, causing a significant increase in growth cone size. This response time is similar to that observed with typical axon guidance molecules (Fournier et al., 2000; Aizawa et al., 2001; Dent et al., 2004). However, the behavior elicited by Wnt3a is distinct, because instead of promoting extension or repulsion, Wnt3a reduces axon extension by increasing growth cone pausing and growth cone size and branching. Therefore, the axon behavior observed on neurons exposed to Wnt is more consistent with a role for Wnt3a as a target-derived signal that retrogradely regulates terminal arborization of axons before synapses begin to form.

How does Wnt3a influence axon behavior? Signaling through Wnt receptors results in the activation of Dvl. In the canonical Wnt pathway, Dvl activation leads to inhibition of Gsk $3 \beta$, accumulation of $\beta$-catenin, and transcriptional activation through the LEF/TCF transcription factors (Reya et al., 2003). Although Dvll is required for axon remodeling and inhibition of Gsk $3 \beta$ mimics Wnt-induced remodeling, our new studies show that transcription is not required. Interestingly, expression of fulllength or a mutant $\beta$-catenin lacking its transactivating domain fully mimics the effect of Wnts on growth cone size. Thus, the Wnt $3 a-\beta$-catenin pathway, through inhibition of Gsk $3 \beta$, directly signals to the cytoskeleton.

During remodeling, Wnt3a causes dramatic changes in the organization of MTs. In contrast to the typical splayed distribution of MTs in growth cones, Wnt3a-treated growth cones contain looped MTs. Conversely, Dvl1 mutant neurons, which do 

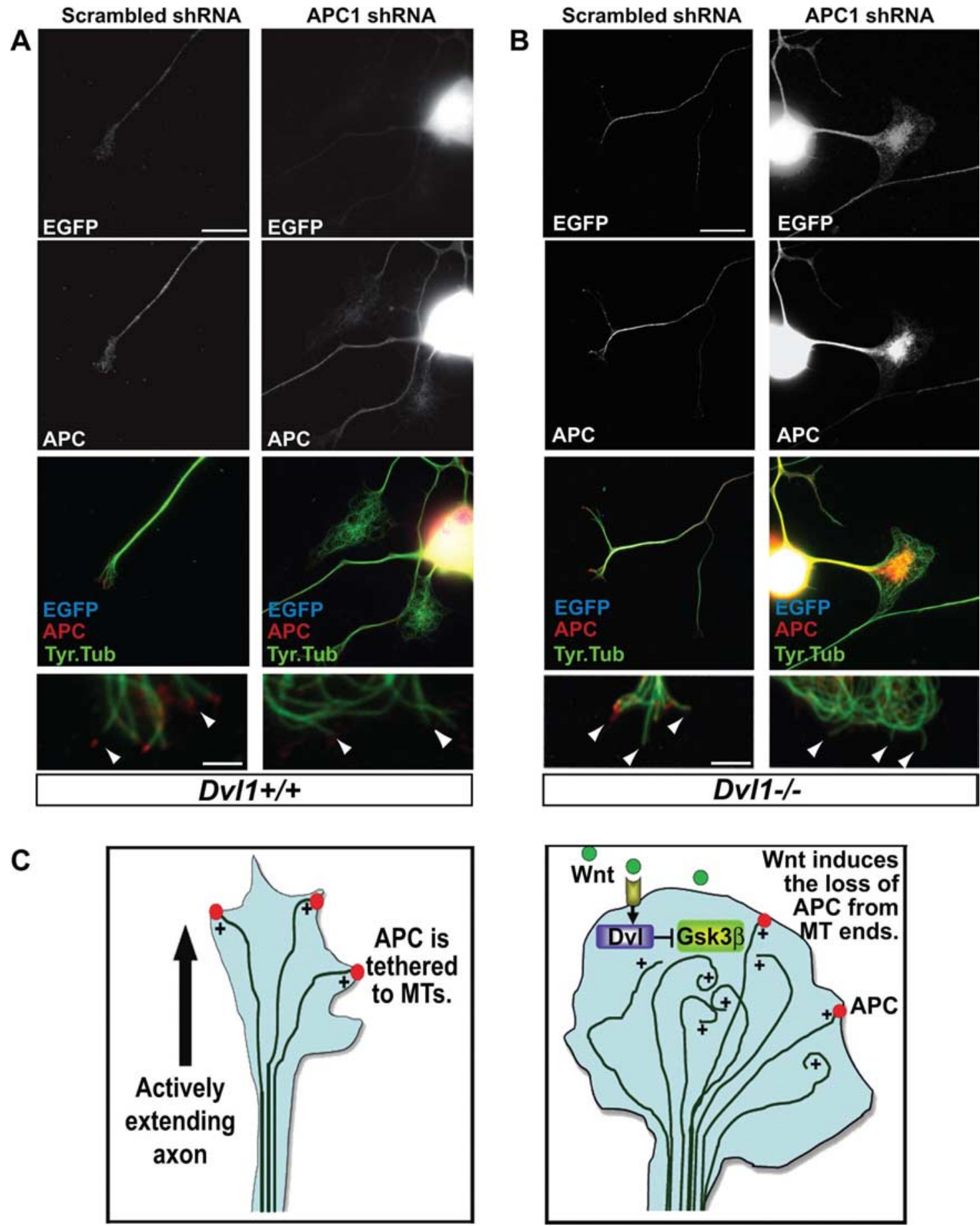

Figure 7. APC knockdown in wild-type or Dv/1 mutant DRG neurons induces the formation of looped microtubules and enlargement of growth cone size. $A$, DRG neurons coexpressing scrambled shRNA construct and EGFP have small growth cones like control neurons, whereas DRG neurons coexpressing an APC1 shRNA construct and EGFP have enlarged growth cones with looped MTs. Growth cones show the significant loss of APC at MT tips (arrowheads). Scale bars: top, $30 \mu \mathrm{m}$; bottom, $5 \mu \mathrm{m}$. See Results for quantifications of number of growth cones with looped MTs, size of growth cones, and percentage of MT tips containing APC. B, Dvl1 mutant DRG neurons exhibit enlarged growth cones with looped MT when coexpressing APC1 shRNA construct and EGFP. In contrast, Dv17 mutant DRG neurons coexpressing scrambled shRNA constructand EGFP exhibit growth cones with comparable size to control neurons. Growth cones show the significant loss of APC at MT tips (arrowheads). Scale bars: top, $30 \mu \mathrm{m}$; bottom, $5 \mu \mathrm{m}$. See Results for quantification of percentage of MT tips with APC per growth cone. C, Model for Wnt signaling in the regulation of MT directionality. Activation of the Wnt-Dvl1 signaling pathway regulates APC localization on MT plus-ends at the periphery of the growth cone, resulting in MT looping and enlargement of growth cones.

not remodel in the presence of Wnts, exhibit typical splayed MTs in the presence of Wnt3a. Our data strongly suggest that Wntmediated axon remodeling is caused by increased MT looping at remodeled growth cones.

To what extent does MT looping contribute to growth cone remodeling? Wnt3a increases membrane protrusion, suggesting changes in actin dynamics. Our experiments, using low levels of latrunculin B, indicate that Wnt3a can still induce MT looping and growth cone enlargement when actin dynamics is blocked. Although a possible effect of Wnt on actin cannot be excluded, our results strongly suggest that MT reorganization significantly contributed to Wnt-mediated remodeling at the growth cone. 
MT looping could directly contribute to changes in growth cone behavior observed during terminal remodeling. Looped MTs have been previously observed in pausing and enlarged growth cones (Tsui et al., 1984; Tanaka and Kirschner, 1991; Dent et al., 1999; Dent and Kalil, 2001; Schaefer et al., 2002). Interestingly, looped MTs have also been observed in synaptic boutons at the Drosophila NMJ (Packard et al., 2002), where they are implicated in the regulation of synaptic growth (Roos et al., 2000). MT looping could result from the continuous polymerization of tubulin in a paused growth cone, which could cause MTs to bend backwards when they reach the leading edge. Alternatively, looped MTs could form by their loss of directional growth because of direct changes on the microtubule cytoskeleton or by influencing actin retrograde flow. Our time-lapse recordings of neurons expressing EB3-GFP show that Wnt3a and Dvl1 increase the number of MTs that bend and grow across the growth cone instead of exhibiting a typical splayed behavior observed during axon outgrowth. In Wnt3a-treated neurons, some MTs kink several times during polymerization at the center of the growth cone, instead of growing with a persistent trajectory as observed in control growth cones. These changes in MT behavior are observed before MTs reach the periphery of the growth cone, consistent with the notion that Wnt signaling regulates the direction of MT growth. Importantly, this loss of directionality could contribute to the continued MT growth, resulting in increased content of MTs, which are no longer tethered to the leading edge of the growth cone.

Gsk3 $\beta$ has been implicated in the regulation of axon growth. In cerebellar granule cells, mossy fibers, and DRG neurons, as reported here, inhibition of Gsk $3 \beta$ results in decreased axon extension and increased growth cone size (Lucas et al., 1998; Goold et al., 1999; Hall et al., 2000; Krylova et al., 2002). However, inhibition of Gsk3 $\beta$ has also been reported to stimulate axon outgrowth (Zhou et al., 2004). A recent study has provided a possible explanation for this apparent paradox. Different levels of Gsk3 $\beta$ inhibition elicit different responses in the behavior of axons as weak inhibition results in axon outgrowth, whereas strong inhibition decreases extension (Kim et al., 2006). Interestingly, Wnt3a has been reported to increase axon outgrowth in NGFresponsive DRG sensory neurons after long exposure (Lu et al., 2004). These results, together with ours, suggest that the same Wnt protein can elicit distinct responses, possibly by inducing different levels of Gsk3 $\beta$ inhibition depending on the cellular context and/or cell type.

Wnt signaling regulates MT looping and growth cone remodeling through changes in the MT plus-end-binding protein APC. At the leading edge of remodeled growth cones, Wnt signaling through inhibition of Gsk3 $\beta$ decreases the number of MT plusends containing endogenous APC. Interestingly, Wnt3a does not affect the levels of other MT plus-end-binding proteins such as CLIP170 and EB1, which have been shown to promote MT rescue (Komarova et al., 2002), MT stability and elongation (Wen et al., 2004; Strickland et al., 2005). The specific effect of Wnt on APC is observed within $30 \mathrm{~min}$, just before a significant increase in growth cone size and in the number of looped MTs becomes evident. Importantly, knockdown of APC in DRG neurons induces MT looping and the formation of large growth cones as observed with Wnt3a. Together, our results demonstrate that Wnt3a modulates MT directionality by specifically affecting APC at MT plus-ends (Fig. 7C) and reveal a novel function of APC in the regulation of MT growth direction.

APC at the axon tip modulates the rate of axon elongation, pausing, and remodeling. APC has previously been implicated in
MT capture at the leading edge of migrating cells (Watanabe et al., 2004; Reilein and Nelson, 2005), and its localization at MT plus-ends is crucial for cell polarization (Etienne-Manneville and Hall, 2003; Etienne-Manneville et al., 2005). Moreover, the localization of APC at the tip of neurites is essential for axon determination during early stages of neurite outgrowth (Shi et al., 2004). In extending neurons, APC is localized at the growth cones of actively extending neurites (Zhou et al., 2004), and the levels of APC at the end of neuronal processes correlate with increased neurite growth (Votin et al., 2005). Consistent with these findings, asymmetric inactivation of APC by microscale chromophore-assisted laser inactivation results in growth cone turning attributable to axon extension on the side containing APC (Koester et al., 2007). But how is APC localization regulated? Studies in migrating fibroblasts indicate that Wnt5a, a noncanonical Wnt, induces the accumulation of APC at the leading edge in the direction of migration through the activation of atypical PKC (aPKC) (Schlessinger et al., 2007). Interestingly, a recent study showed that in axons, Wnt5a also activates aPKC to determine axon specification, a process that requires rapid outgrowth (Zhang et al., 2007). Although the role of APC in Wnt5amediated cell protrusion or axon extension has not been examined, our studies suggest a central role for APC in Wnt-mediated axon responses. Distinct Wnt pathways may determine axon outgrowth versus growth cone pausing and remodeling. Activation of a Wnt pathway that requires aPKC stimulates rapid axon extension. In contrast, activation of a divergent canonical pathway decreases APC from MT plus-ends, leading to the loss of MT growth directionality, resulting in axon remodeling. Here we provide the first evidence that Wnts can directly affect the localization of APC to induce changes in axon behavior.

\section{References}

Ahmad-Annuar A, Ciani L, Simeonidis I, Herreros J, Fredj NB, Rosso SB, Hall A, Brickley S, Salinas PC (2006) Signaling across the synapse: a role for Wnt and Dishevelled in presynaptic assembly and neurotransmitter release. J Cell Biol 174:127-139.

Aizawa H, Wakatsuki S, Ishii A, Moriyama K, Sasaki Y, Ohashi K, SekineAizawa Y, Sehara-Fujisawa A, Mizuno K, Goshima Y, Yahara I (2001) Phosphorylation of cofilin by LIM-kinase is necessary for semaphorin 3A-induced growth cone collapse. Nat Neurosci 4:367-373.

Bienz M (2002) The subcellular destinations of APC proteins. Nat Rev Mol Cell Biol 3:328-338.

Campbell DS, Holt CE (2001) Chemotropic responses of retinal growth cones mediated by rapid local protein synthesis and degradation. Neuron 32:1013-1026.

Capelluto DG, Kutateladze TG, Habas R, Finkielstein CV, He X, Overduin M (2002) The DIX domain targets dishevelled to actin stress fibres and vesicular membranes. Nature 419:726-729.

Ciani L, Salinas PC (2005) WNTs in the vertebrate nervous system: from patterning to neuronal connectivity. Nat Rev Neurosci 6:351-362.

Ciani L, Krylova O, Smalley MJ, Dale TC, Salinas PC (2004) A divergent canonical WNT-signaling pathway regulates microtubule dynamics: dishevelled signals locally to stabilize microtubules. J Cell Biol 164:243-253.

Cohen P, Goedert M (2004) GSK3 inhibitors: development and therapeutic potential. Nat Rev Drug Discov 3:479-487.

Dent EW, Kalil K (2001) Axon branching requires interactions between dynamic microtubules and actin filaments. J Neurosci 21:9757-9769.

Dent EW, Callaway JL, Szebenyi G, Baas PW, Kalil K (1999) Reorganization and movement of microtubules in axonal growth cones and developing interstitial branches. J Neurosci 19:8894-8908.

Dent EW, Barnes AM, Tang F, Kalil K (2004) Netrin-1 and semaphorin 3A promote or inhibit cortical axon branching, respectively, by reorganization of the cytoskeleton. J Neurosci 24:3002-3012.

Etienne-Manneville S, Hall A (2003) Cdc42 regulates GSK-3beta and adenomatous polyposis coli to control cell polarity. Nature 421:753-756.

Etienne-Manneville S, Manneville JB, Nicholls S, Ferenczi MA, Hall A (2005) 
Cdc42 and Par6-PKCzeta regulate the spatially localized association of Dlg1 and APC to control cell polarization. J Cell Biol 170:895-901.

Fournier AE, Kalb RG, Strittmatter SM (2000) Rho GTPases and axonal growth cone collapse. Methods Enzymol 325:473-482.

Galjart N (2005) CLIPs and CLASPs and cellular dynamics. Nat Rev Mol Cell Biol 6:487-498.

Gärtner A, Huang X, Hall A (2006) Neuronal polarity is regulated by glycogen synthase kinase-3 (GSK-3beta) independently of Akt/PKB serine phosphorylation. J Cell Sci 119:3927-3934.

Goold RG, Owen R, Gordon-Weeks PR (1999) Glycogen synthase kinase 3beta phosphorylation of microtubule-associated protein $1 \mathrm{~B}$ regulates the stability of microtubules in growth cones. J Cell Sci 112:3373-3384.

Gordon MD, Nusse R (2006) Wnt signaling: multiple pathways, multiple receptors, and multiple transcription factors. J Biol Chem 281:22429-22433.

Hall AC, Lucas FR, Salinas PC (2000) Axonal remodeling and synaptic differentiation in the cerebellum is regulated by WNT-7a signaling [see comments]. Cell 100:525-535.

Hasaka TP, Myers KA, Baas PW (2004) Role of actin filaments in the axonal transport of microtubules. J Neurosci 24:11291-11301.

Kalil K, Dent EW (2004) Hot + TIPS: guidance cues signal directly to microtubules. Neuron 42:877-879.

Kalil K, Dent EW (2005) Touch and go: guidance cues signal to the growth cone cytoskeleton. Curr Opin Neurobiol 15:521-526.

Kim WY, Zhou FQ, Zhou J, Yokota Y, Wang YM, Yoshimura T, Kaibuchi K, Woodgett JR, Anton ES, Snider WD (2006) Essential roles for GSK-3s and GSK-3-primed substrates in neurotrophin-induced and hippocampal axon growth. Neuron 52:981-996.

Kleitman N, Wood PM, Bunge RP (1991) Tissue culture methods for the study of myelination. In: Culturing nerve cells (Banker G, Goslin K, eds), pp 351-353. Cambridge, MA: MIT.

Koester MP, Müller O, Pollerberg GE (2007) Adenomatous polyposis coli is differentially distributed in growth cones and modulates their steering. J Neurosci 27:12590-12600.

Komarova YA, Akhmanova AS, Kojima S, Galjart N, Borisy GG (2002) Cytoplasmic linker proteins promote microtubule rescue in vivo. J Cell Biol 159:589-599.

Krylova O, Messenger MJ, Salinas PC (2000) Dishevelled-1 regulates microtubule stability: a new function mediated by glycogen synthase kinase3beta. J Cell Biol 151:83-94.

Krylova O, Herreros J, Cleverley KE, Ehler E, Henriquez JP, Hughes SM, Salinas PC (2002) WNT-3, expressed by motoneurons, regulates terminal arborization of neurotrophin-3-responsive spinal sensory neurons. Neuron 35:1043-1056.

Lu W, Yamamoto V, Ortega B, Baltimore D (2004) Mammalian Ryk is a Wnt coreceptor required for stimulation of neurite outgrowth. Cell 119:97-108.

Lucas FR, Goold RG, Gordon-Weeks PR, Salinas PC (1998) Inhibition of GSK-3beta leading to the loss of phosphorylated MAP-1B is an early event in axonal remodelling induced by WNT-7a or lithium. J Cell Sci 111:1351-1361.

Nakagawa H, Koyama K, Murata Y, Morito M, Akiyama T, Nakamura Y (2000) EB3, a novel member of the EB1 family preferentially expressed in the central nervous system, binds to a CNS-specific APC homologue. Oncogene 19:210-216.

Packard M, Koo ES, Gorczyca M, Sharpe J, Cumberledge S, Budnik V (2002) The Drosophila Wnt, wingless, provides an essential signal for pre- and postsynaptic differentiation. Cell 111:319-330.

Reilein A, Nelson WJ (2005) APC is a component of an organizing template for cortical microtubule networks. Nat Cell Biol 7:463-473.

Reya T, Duncan AW, Ailles L, Domen J, Scherer DC, Willert K, Hintz L, Nusse $\mathrm{R}$, Weissman IL (2003) A role for Wnt signalling in self-renewal of haematopoietic stem cells. Nature 423:409-414.

Ring DB, Johnson KW, Henriksen EJ, Nuss JM, Goff D, Kinnick TR, Ma ST, Reeder JW, Samuels I, Slabiak T, Wagman AS, Hammond ME, Harrison SD (2003) Selective glycogen synthase kinase 3 inhibitors potentiate insulin activation of glucose transport and utilization in vitro and in vivo. Diabetes 52:588-595.
Rogers SL, Rogers GC, Sharp DJ, Vale RD (2002) Drosophila EB1 is important for proper assembly, dynamics, and positioning of the mitotic spindle. J Cell Biol 158:873-884.

Roos J, Hummel T, Ng N, Klämbt C, Davis GW (2000) Drosophila Futsch regulates synaptic microtubule organization and is necessary for synaptic growth. Neuron 26:371-382.

Salinas PC (2007) Modulation of the microtubule cytoskeleton: a role for a divergent canonical Wnt pathway. Trends Cell Biol 17:333-342.

Schaefer AW, Kabir N, Forscher P (2002) Filopodia and actin arcs guide the assembly and transport of two populations of microtubules with unique dynamic parameters in neuronal growth cones. J Cell Biol 158:139-152.

Schlessinger K, McManus EJ, Hall A (2007) Cdc42 and noncanonical Wnt signal transduction pathways cooperate to promote cell polarity. J Cell Biol 178:355-361.

Shi SH, Cheng T, Jan LY, Jan YN (2004) APC and GSK-3beta are involved in $\mathrm{mPar} 3$ targeting to the nascent axon and establishment of neuronal polarity. Curr Biol 14:2025-2032.

Stepanova T, Slemmer J, Hoogenraad CC, Lansbergen G, Dortland B, De Zeeuw CI, Grosveld F, van Cappellen G, Akhmanova A, Galjart N (2003) Visualization of microtubule growth in cultured neurons via the use of EB3-GFP (end-binding protein 3-green fluorescent protein). J Neurosci 23:2655-2664.

Strickland LI, Wen Y, Gundersen GG, Burgess DR (2005) Interaction between EB1 and p150glued is required for anaphase astral microtubule elongation and stimulation of cytokinesis. Curr Biol 15:2249-2255.

Tanaka EM, Kirschner MW (1991) Microtubule behavior in the growth cones of living neurons during axon elongation. J Cell Biol 115:345-363.

Tirnauer JS, O’Toole E, Berrueta L, Bierer BE, Pellman D (1999) Yeast Bimlp promotes the G1-specific dynamics of microtubules. J Cell Biol 145:993-1007.

Torres MA, Nelson WJ (2000) Colocalization and redistribution of dishevelled and actin during Wnt-induced mesenchymal morphogenesis. J Cell Biol 149:1433-1442.

Tsui HT, Lankford KL, Ris H, Klein WL (1984) Novel organization of microtubules in cultured central nervous system neurons: formation of hairpin loops at ends of maturing neurites. J Neurosci 4:3002-3013.

Umemori H, Linhoff MW, Ornitz DM, Sanes JR (2004) FGF22 and its close relatives are presynaptic organizing molecules in the mammalian brain. Cell 118:257-270.

Votin V, Nelson WJ, Barth AI (2005) Neurite outgrowth involves adenomatous polyposis coli protein and \{beta\}-catenin. J Cell Sci 118:5699-5708.

Wakatsuki T, Schwab B, Thompson NC, Elson EL (2001) Effects of cytochalasin D and latrunculin B on mechanical properties of cells. J Cell Sci 114:1025-1036.

Watanabe T, Wang S, Noritake J, Sato K, Fukata M, Takefuji M, Nakagawa M, Izumi N, Akiyama T, Kaibuchi K (2004) Interaction with IQGAP1 links APC to Rac1, Cdc42, and actin filaments during cell polarization and migration. Dev Cell 7:871-883.

Wen Y, Eng CH, Schmoranzer J, Cabrera-Poch N, Morris EJ, Chen M, Wallar BJ, Alberts AS, Gundersen GG (2004) EB1 and APC bind to mDia to stabilize microtubules downstream of Rho and promote cell migration. Nat Cell Biol 6:820-830.

Zhang X, Zhu J, Yang G-Y, Wang Q-J, Qian L, Chen Y-M, Chen F, Tao Y, Hu H-S, Wang T, Luo Z-G (2007) Dishevelled promotes axon differentiation by regulating atypical protein kinase C. Nat Cell Biol 9:743-754.

Zhou FQ, Zhou J, Dedhar S, Wu YH, Snider WD (2004) NGF-induced axon growth is mediated by localized inactivation of GSK-3beta and functions of the microtubule plus end binding protein APC. Neuron 42:897-912.

Zmuda JF, Rivas RJ (2000) Actin disruption alters the localization of tau in the growth cones of cerebellar granule neurons. J Cell Sci 113:2797-2809.

Zou Y (2006) Navigating the anterior-posterior axis with Wnts. Neuron 49:787-789.

Zumbrunn J, Kinoshita K, Hyman AA, Näthke IS (2001) Binding of the adenomatous polyposis coli protein to microtubules increases microtubule stability and is regulated by GSK3 beta phosphorylation. Curr Biol 11:44-49. 